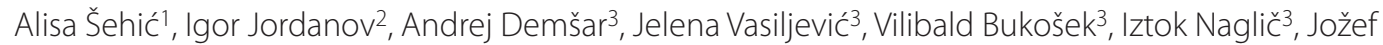

Medved ${ }^{3}$, Barbara Simončič 3

${ }^{1}$ AquafilSLO d. o. O., Letališka 15, 1000 Ljubljana, Slovenia

2Ss. Cyril and Methodius University, Faculty of Technology and Metallurgy, Ruger Boskovic 16, 1000 Skopje,

Macedonia

${ }^{3}$ University of Ljubljana, Faculty of Natural Sciences and Engineering, Aškerčeva 12, 1000 Ljubljana, Slovenia

\title{
Influence of Flame Retardant Additive on Thermal Behaviour and Stability of Fibre-Forming Polyamide 6
}

\author{
Original Scientific Article
}

Received 03-2016 • Accepted 04-2016

\begin{abstract}
This work presents a study of the influence of diethyl aluminum phosphinate (EOP) and sodium alumino silicate (ZP) as the novel green flame retardant spinning additives on the thermal properties of polyamide 6 (PA6) fibres. The PA6/additive composite filaments were prepared at $4 \mathrm{wt} \%$ concentration of additives and their mixture by melt spinning. The results show that the additives were physically incorporated into the PA6 filament, resulting in an insignificant change of the melting temperature. The presence of EOP decreased $T_{\text {onset }}$ and increased $T_{\max 2}$ compared to pure PA6, which indicates that the degradation process started at lower temperature, whereas the thermo-oxidative stability in the second decomposition step increased. Contrary to EOP, ZP did not cause any noticeable changes in the decomposition temperatures comparing to pure PA6, but significantly increased the final char amount. Both phenomena were also observed when the additives were used in combination. Whereas EOP did not significantly affect the mechanical filament properties, the incorporation of ZP resulted in the reinforcement of fibres.

Keywords: polyamide 6, spinning, filament, flame retardant additive, thermal stability
\end{abstract}

\section{Introduction}

Polyamide 6 (PA6) is a widely used polymer which is synthesised by ring-opening polymerisation of caprolactam. PA6 fibres are tough, possessing high tensile strength, elasticity and lustre. The application of PA6 can be found in various sectors, e.g. transportation (automotive industry), home textiles, clothes and construction. However, due to its organic nature, PA6 is flammable, which represents its important disadvantage. At this time, no acceptable flame-retardant solutions exist for PA6 fibres mainly due to the processing issues, i.e. melt spinning of the fibres containing flame retardant additives [1-3].

Flame retardancy of fibres or fabrics can be achieved by using several approaches: coatings, back coatings

Correspnding author:

Prof. DrSc Barbara Simončič

Phone: ++3861 2003231

E-mail: barbara.simoncic@ntf.uni-lj.si and/or finishing treatments (reactive or unreactive treatments) are applied onto fabrics (nonwovens, knitted or woven fabrics); materials able to dissipate a significant amount of heat (e.g. metal foil) are layered onto the fabric; in the case of synthetic fibres, the grafting of flame retardant (FR) molecules on the polymeric chain or the direct incorporation of FR additives during the processing step of the fibre can be considered [4-11].

The aim of our study was to produce a PA6 filament with increased thermal stability by using the commercially available flame-retardant additives based on phosphorus and silica. The PA6/additive composite filaments were produced in a melt spinning process. The influence of the amount of additives in the composite filament on the thermal and mechanical properties of composite filaments was investigated.

Tekstilec, 2016, 59(2), 149-155

DOI: 10.14502/Tekstilec2016.59.149-155 


\section{Experimental}

\subsection{Materials}

The flame retardant additives used in this study were commercially available products Exolit OP1312, diethyl aluminum phosphinate (EOP), supplied by Clariant and Zeolite ZP - 4A TSR, sodium alumino silicate (ZP), supplied by Silkem. The polyamide 6 polymer (PA6) with 2.4 relative viscosity (Aquamid) was supplied by Aquafil.

\subsection{Masterbatch preparation}

The pellets of PA6/EOP with 80/20 (w/w) composition and PA6/ZP with 90/10 (w/w) composition were used in combination with pure PA6 pellets to obtain different composite formulations. To have a minimal effect on the mechanical fibre properties, the total amount of additives was fixed to $4 \mathrm{wt} \%$. The masterbatch was dried for $5 \mathrm{~h}$ at $90^{\circ} \mathrm{C}$ prior to use.

\subsection{Processing of fibres}

The pure PA6 and PA6/additive composite filaments were produced in a melt spinning process using a laboratory melt spinning device (Extrusion System Ltd; Figure 1). The spinning temperature was $250^{\circ} \mathrm{C}$ in all zones of extruder, spinning pump and spin pack. The spinneret had 10 holes with $0.35 \mathrm{~mm}$ in diameter. The godet velocity was $70 \mathrm{~m} / \mathrm{min}$ and the winding speed was $350 \mathrm{~m} / \mathrm{min}$. The sample codes are presented in Table 1.

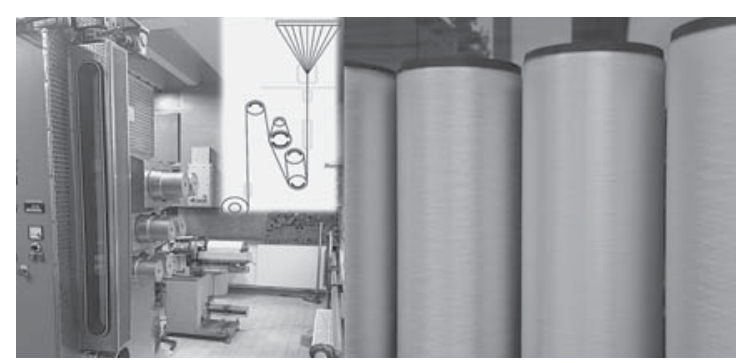

Figure 1: Melt spinning device and scheme of spinning process (left) and final bobbins (right)

\subsection{Analytical methods}

\section{Scanning electron microscopy (SEM)}

SEM images were obtained for all samples using a JEOL JSM 6060 LV scanning electron microscope, operating with a primary electron beam accelerated at $10 \mathrm{kV}$ and with the working distance of $17 \mathrm{~mm}$. The samples were coated with a thin layer of gold before the observation to increase the clarity of images.

\section{Optical microscopy}

Optical images of samples were made with an optical microscope and Laboratory tool Axio Vision REL Leica Microscopy software was used to made photos.

\section{Fourier-transform infrared spectroscopy (FTIR)}

FTIR spectra were obtained on a Spectrum GX I spectrophotometer (Perkin Elmer, Great Britain) equipped with an attenuated total reflection (ATR) cell with a diamond crystal $(n=2.0)$. The spectra were recorded over the range from 4,000-600 $\mathrm{cm}^{-1}$ at the resolution of $4 \mathrm{~cm}^{-1}$.

\section{Thermogravimetric (TG) and differential scan- ning calorimetric (DSC) analyses}

The TG and DSC analyses were performed using an STA 449c Jupiter instrument (NETZSCH) at the temperatures ranging from ambient temperature to $800^{\circ} \mathrm{C}$ at the heating and cooling rates of $10^{\circ} \mathrm{C} / \mathrm{min}$ in an open alumina pan (sample mass $=1 \mathrm{mg}$ ) with the samples under an air atmosphere. The DSC analyses were also performed from $0-300{ }^{\circ} \mathrm{C}$ in a Mettler Toledo instrument to measure the glass transition temperature and influence on the crystallinity of fibres. The heating and cooling rates were $10^{\circ} \mathrm{C} / \mathrm{min}$ in an open alumina pan (sample mass $=15 \mathrm{mg}$ ) with the samples under a nitrogen atmosphere $(10 \mathrm{~mL} / \mathrm{min})$.

Three measurements were recorded for each sample and the mean value of the measured quantities was calculated.

Table 1: Codes of samples according to concentration of flame retardant additive in filament

\begin{tabular}{|l|c|c|c|}
\hline \multicolumn{1}{|c|}{ Sample code } & PA6 [wt\%] & EOP [wt\%] & ZP [wt\%] \\
\hline PA & 100 & 0 & 0 \\
\hline PA/4P & 96 & 4 & 0 \\
\hline PA/2P+2SI & 96 & 2 & 2 \\
\hline PA/4SI & 96 & 0 & 4 \\
\hline
\end{tabular}




\section{Mechanical and dynamic mechanical analysis (DMA)}

Tensile strength and elongation at break were measured on a STATIMAT dynamometer (Textechno). The DMA tests were performed on TA equipment DMA Q800 (USA), with a controlled gas-cooling accessory (GCA). The samples were heated from $0-220^{\circ} \mathrm{C}$ at the constant rate of $2{ }^{\circ} \mathrm{C} / \mathrm{min}$. During the heating, the test samples were deformed (oscillated) at constant amplitude (strain) of $10 \mu \mathrm{m}$ at a frequency of $10 \mathrm{~Hz}$ and the dynamic mechanical properties were measured.

\section{Results and discussion}

\section{Filament analysis}

The SEM/EDS analysis was used to investigate the effect of the applied additives on the morphology of the PA6/additive composite filaments. As it can be seen in Figure 2 and Table 2, both additives were successfully incorporated into the filaments. The optical microscope photographs that show crosssectional and longitudinal view of filament samples (Figure 3) also reveal that the incorporation of additives caused visible dark spots in the filament.
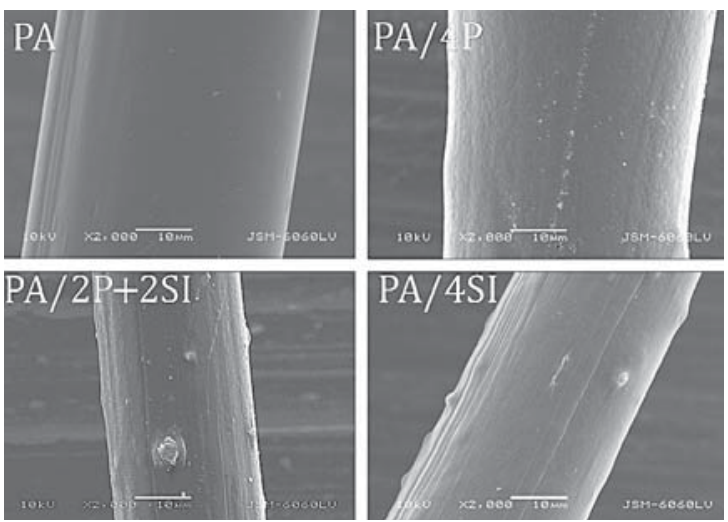

Figure 2: Representative SEM images of filament samples

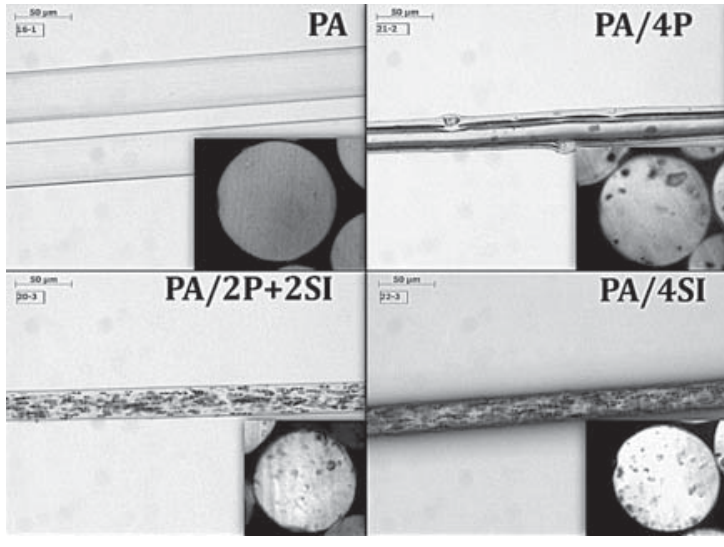

Figure 3: Optical microscopy analysis of filament samples

The FTIR spectra of samples are presented in Figure 4. The ATR spectrum of the PA sample exhibited characteristic bands at $3293 \mathrm{~cm}^{-1}$ and $3062 \mathrm{~cm}^{-1}$ due to the N-H stretching, at $2920 \mathrm{~cm}^{-1}$ and $2851 \mathrm{~cm}^{-1}$ due to the $\mathrm{CH}_{2}$ stretching, at $1637 \mathrm{~cm}^{-1}$ due to the $\mathrm{C}=\mathrm{O}$ stretching and at $1534 \mathrm{~cm}^{-1}$ due to the $\mathrm{N}-\mathrm{H}$ deformation. These bands remained clearly visible in the spectra of the PA6 composite filaments.

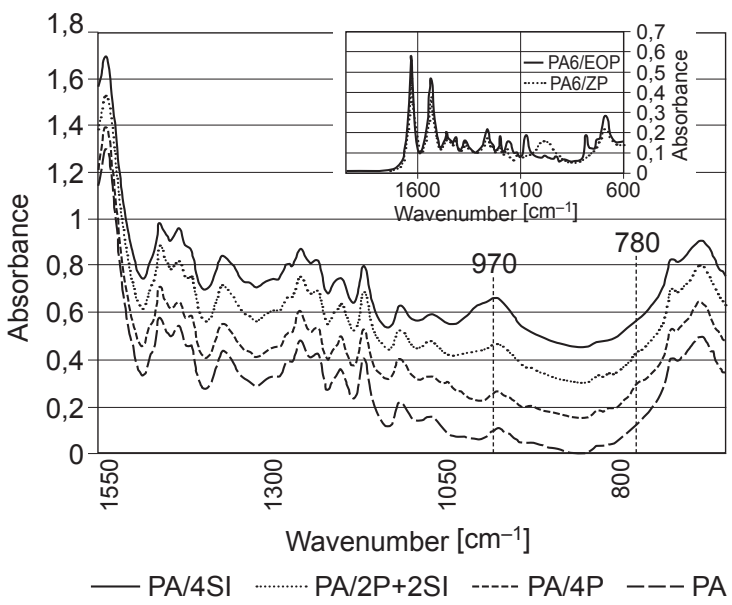

Figure 4: FTIR spectra of filament samples and of PA6/EOP with 80/20 (w/w) composition and PA6/ZP with 90/10 (w/w) composition (insert)

Table 2: Elemental surface composition of filament samples. Results were obtained by EDS analysis

\begin{tabular}{|l|c|c|c|c|c|c|c|}
\hline Sample code & $\mathrm{C}[\mathrm{wt} \%]$ & $\mathrm{N}[\mathrm{wt} \%]$ & $\mathrm{O}[\mathrm{wt} \%]$ & $\mathrm{Al}[\mathrm{wt} \%]$ & $\mathrm{P}[\mathrm{wt} \%]$ & $\mathrm{Na}[\mathrm{wt} \%]$ & $\mathrm{Si}[\mathrm{wt} \%]$ \\
\hline $\mathrm{PA}$ & 75.1 & 13.0 & 12.0 & 0.0 & 0.0 & 0.0 & 0.0 \\
\hline $\mathrm{PA} / 4 \mathrm{P}$ & 61.1 & 5.6 & 27.0 & 2.2 & 4.2 & 0.0 & 0.0 \\
\hline $\mathrm{PA} / 2 \mathrm{P}+2 \mathrm{SI}$ & 39.9 & 0.0 & 36.3 & 10.0 & 0.0 & 2.7 & 11.0 \\
\hline $\mathrm{PA} / 4$ SI & 30.8 & 0.0 & 35.5 & 14.4 & 0.0 & 3.4 & 15.9 \\
\hline
\end{tabular}


Table 3: Characteristic crystallisation values of pure PA6 and PA6/additive composite filaments

\begin{tabular}{|l|c|c|c|c|c|c|}
\hline \multicolumn{1}{|c|}{ Sample code } & PA6 [wt\%] & $\begin{array}{c}\text { Additive } \\
{[\mathrm{wt} \%]}\end{array}$ & $\mathrm{T}_{\mathrm{m} 1}{ }^{\mathrm{a})}\left[{ }^{\circ} \mathrm{C}\right]$ & $\left.\mathrm{T}_{\mathrm{c}} \mathrm{b}\right)\left[{ }^{\circ} \mathrm{C}\right]$ & $\mathrm{T}_{\mathrm{m} 2}{ }^{\mathrm{c})}\left[{ }^{\circ} \mathrm{C}\right]$ & $\mathrm{a}_{\mathrm{DSC}}{ }^{\mathrm{d})}[\%]$ \\
\hline $\mathrm{PA}$ & 100 & 0 & 224.7 & 188.5 & 221.7 & 33.7 \\
\hline $\mathrm{PA} / 4 \mathrm{P}$ & 96 & 4 & 222.9 & 187.9 & 221.5 & 30.6 \\
\hline $\mathrm{PA} / 2 \mathrm{P}+2 \mathrm{SI}$ & 96 & 4 & 223.6 & 188.3 & 221.6 & 32.6 \\
\hline $\mathrm{PA} / 4 \mathrm{SI}$ & 96 & 4 & 223.8 & 188.7 & 221.2 & 35.3 \\
\hline
\end{tabular}

a)melting temperature of first heating scan; b)crystallisation temperature; c)melting temperature of the second heating scan; d)degree of crystallinity

In contrast to the $4000-1500 \mathrm{~cm}^{-1}$ spectral region, in which the spectra are very similar to each other, the presence of EOP caused the appearance of a slight band at $780 \mathrm{~cm}^{-1}$, corresponding to the $\mathrm{P}-\mathrm{O}-\mathrm{C}$ stretching, and the presence of $\mathrm{ZP}$ gave rise to pronounced changes in the $1100-900 \mathrm{~cm}-1$ spectral region due to the asymmetric stretching vibrations of $\mathrm{Si}-\mathrm{O}-\mathrm{Si}$. These bands are clearly seen in the spectra of PA6/EOP with $80 / 20(\mathrm{w} / \mathrm{w})$ composition and PA6/ZP with 90/10 (w/w) composition.

\section{Thermal properties}

The results of the DSC analysis ranging from 0$300{ }^{\circ} \mathrm{C}$ are presented in Table 3 . The heating scans were analysed to determine the melting temperature, $\mathrm{T}_{\mathrm{m} 1}$ and $\mathrm{T}_{\mathrm{m} 2}$, and the cooling scans were analysed to determine the crystallisation temperature, Tc. The degree of crystallinity of filaments was calculated according to Rusu and Rusu [12]. The results show that both additives did not alter the melting temperature of PA6, which remained $223 \pm 1{ }^{\circ} \mathrm{C}$, indicating that the additives did not chemically react with the polymer and that they are only physically incorporated into the polymer. The incorporation of EOP shifted the crystallisation temperature to slightly lower temperature, suggesting that the additive caused crystal defects. This phenomenon is accompanied by a lower degree of crystallisation. In contrast to EOP, the incorporation of ZP shifted the crystallisation temperature to slightly higher temperature, suggesting that the ZP particles can represent the nucleation sites for PA6 and therefore accelerate its crystallisation in the composite material. This resulted in the increase of the degree of crystallinity.

\section{Thermo-oxidative stability}

The results of the thermogravimetric analysis of studied samples are summarised in Table 4, and Figures $5 \mathrm{a}$ and $5 \mathrm{~b}$. The thermo-oxidative degradation process of pure PA6 fibres in air includes two main steps. The first step occurs between approximately $320^{\circ} \mathrm{C}$ and $475^{\circ} \mathrm{C}$, and is a consequence of polymer degradation with $\varepsilon$-caprolactam as the main released product, accompanied by the release of other identified volatile compounds such as $\mathrm{CO}, \mathrm{CO}_{2}$, hydrocarbons, $\mathrm{NH}_{3}$, nitrile and ketone derivatives at lower concentrations. The second step occurs between approximately $475{ }^{\circ} \mathrm{C}$ and $660{ }^{\circ} \mathrm{C}$, and is ascribed to the oxidation and aromatisation of aliphatic carbons, accompanied by the release of $\mathrm{CO}_{2}$ and $\mathrm{CO}$ gases. The flame retardant activity of EOP in the composite material decreased $\mathrm{T}_{\text {onset }}$ and increased $\mathrm{T}_{\max 2}$ compared to the untreated PA6, indicating that the thermo-oxidative stability of the composite material at the beginning of the degradation decreased and the thermo-oxidative stability in

Table 4: TG data for untreated and treated filament samples analysed in air atmosphere

\begin{tabular}{|l|c|c|c|c|c|c|}
\hline \multicolumn{1}{|c|}{ Sample code } & $\mathrm{T}_{\text {onset }}{ }^{\mathrm{a})}\left[{ }^{\circ} \mathrm{C}\right]$ & $\mathrm{T}_{\operatorname{maxl}}{ }^{\mathrm{b})}\left[{ }^{\circ} \mathrm{C}\right]$ & $\begin{array}{c}\text { Residue at } \\
\mathrm{T}_{\max 1}[\%]\end{array}$ & $\mathrm{T}_{\max 2}{ }^{\mathrm{c})}\left[{ }^{\circ} \mathrm{C}\right]$ & $\begin{array}{c}\text { Residue at } \\
\mathrm{T}_{\max 2}[\%]\end{array}$ & $\begin{array}{c}\text { Residue at } \\
800{ }^{\circ} \mathrm{C}[\%]\end{array}$ \\
\hline $\mathrm{PA}$ & 382 & 444 & 45.1 & 557 & 11.0 & 6.6 \\
\hline $\mathrm{PA} / 4 \mathrm{P}$ & 361 & 447 & 42.3 & 604 & 9.8 & 5.9 \\
\hline $\mathrm{PA} / 2 \mathrm{P}+2 \mathrm{SI}$ & 365 & 446 & 42.8 & 573 & 10.2 & 7.0 \\
\hline $\mathrm{PA} / 4 \mathrm{SI}$ & 372 & 447 & 45.9 & 534 & 15.4 & 10.4 \\
\hline
\end{tabular}

a)temperature of thermal degradation onset; b)temperature of the first degradation step peak; $c$ ) temperature of the second degradation step peak 


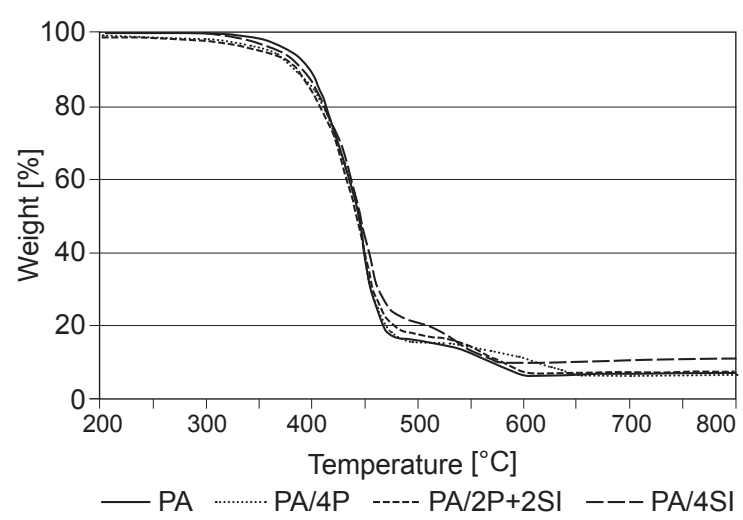

a)

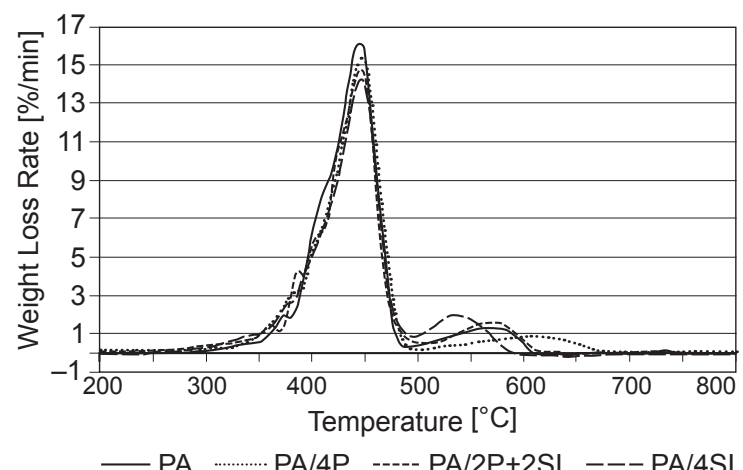

b)

Figure 5: (a) TG and (b) dTG for filament samples analysed in air atmosphere

the second decomposition step increased. EOP did not increase the amount of char residue at $\mathrm{T}_{\max 2}$ and at $800{ }^{\circ} \mathrm{C}$. The presence of $\mathrm{ZP}$ in the composite did not change the decomposition temperatures, but increased the amounts of char residue in both decomposition steps and at $800{ }^{\circ} \mathrm{C}$. This phenomenon is associated with the good thermal stability of silica, which forms a heat barrier in the condensed phase. A different activity of EOP and ZP was also observed in the case of the PA/ $2 \mathrm{P}+2 \mathrm{SI}$ sample, where the additives were incorporated in combination.

\section{Mechanical properties}

In order to examine the potential changes in the mechanical properties due to the incorporation of additive, tensile analysis was conducted on filament samples. In Table 5, the tensile strength and elongation at break are given for pure PA6 and composite filaments. The tenacity of composed filaments decreased compared to the pure PA6 filament. The most significant changes were observed in the sample containing $4 \%$ of the EOP additive. Similar to tenacity, the elongation of composite filaments also decreased in comparison to pure PA6 filaments. The highest fall of elongation was observed in the samples containing $4 \%$ of the $\mathrm{ZP}$ additive.

Table 5: Mechanical properties of filament samples

\begin{tabular}{|l|c|c|}
\hline Sample code & $\begin{array}{c}\text { Tenacity } \\
{[\text { cN/dtex }]}\end{array}$ & $\begin{array}{c}\text { Elongation } \\
{[\%]}\end{array}$ \\
\hline PA & 1.59 & 233.7 \\
\hline PA/4P & 0.39 & 211.9 \\
\hline PA/2P+2SI & 1.11 & 219.4 \\
\hline PA/4SI & 0.97 & 198.7 \\
\hline
\end{tabular}

The results of the DMA analysis are presented in Figure 6. The DMA analysis provides information on the changes at the molecular level, enabling the understanding of the mechanical behaviour of studied samples. The storage modulus is often associated with the "stiffness" of a material and to the Young's

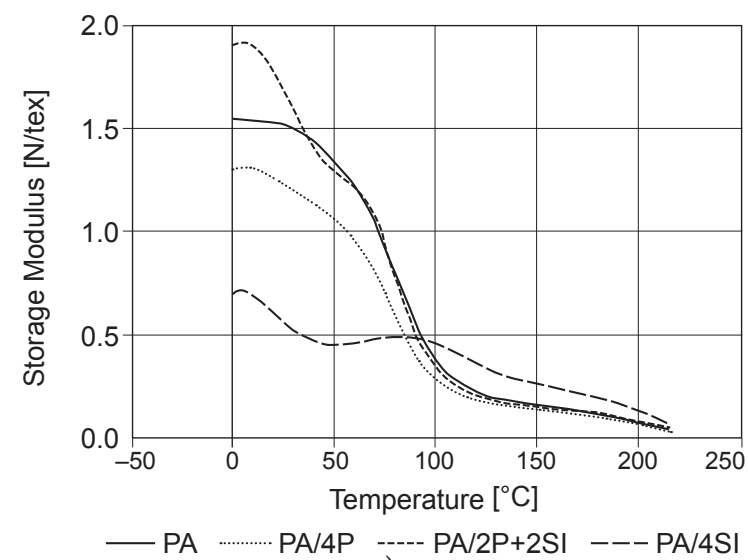

a)

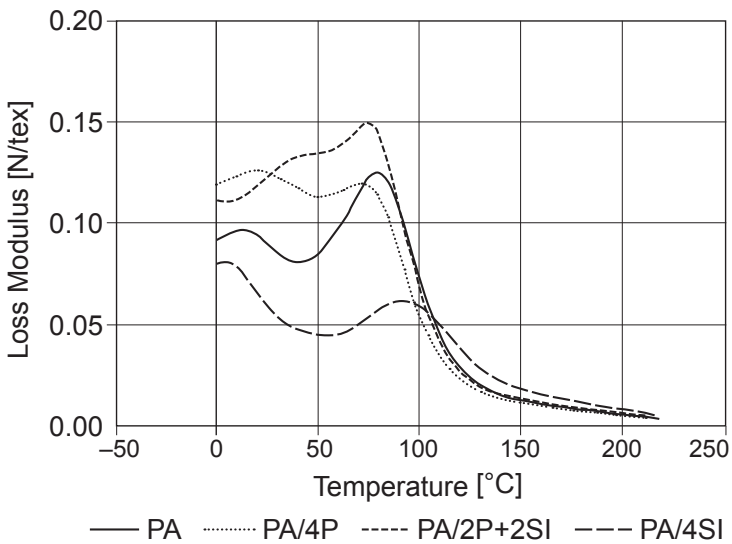

b)

Figure 6: Storage modulus (a) and loss modulus (b) of filament samples 
modulus. The loss modulus is often related to the modulus. The loss modulus is often related to the emission of heat due to "internal friction" and is sensitive to different kinds of molecular motions, relaxation processes, transitions, morphology and other structural heterogeneities. A drop in the storage modulus was seen between $50-100{ }^{\circ} \mathrm{C}$ (Figure 6a), caused by the increased segmental mobility, which is accompanied by the increase in the loss modulus E", with a maximum at approximately $80^{\circ} \mathrm{C}$. This behaviour shows that the transition is accompanied by the emission of heat and loss of elastic properties. The results reveal that $\mathrm{EOP}$ and the mixture of $\mathrm{EOP}+\mathrm{ZP}$ did not significantly influence the shape of the storage modulus curve in the $50-200{ }^{\circ} \mathrm{C}$ temperature region. An exception is the sample PA/4SI for which a significantly lower decrease in the storage modulus was detected in the measured temperature range compared to other samples. Whereas this phenomenon was accompanied by the shift of the peak in the loss modulus (Figure 6b) to higher temperature and lower heat release, it can be concluded that the incorporation of $4 \% \mathrm{ZP}$ into the filament resulted in the reinforcement of filaments.

\section{Conclusion}

The PA6 filament fibres containing flame retardant additives were successfully prepared with the melt spinning process.

The incorporation of additives did not alter the melting temperature of PA6. The presence of EOP slightly decreased the crystallisation temperature, suggesting that the additive caused crystal defects. This phenomenon is accompanied by a lower degree of crystallisation. In contrast to EOP, the presence of ZP slightly increased the crystallisation temperature, suggesting that the ZP particles accelerate the crystallisation of PA6 in the composite material. This resulted in the increase of the degree of crystallinity.

The incorporation of EOP in fibres decreased $\mathrm{T}_{\text {onset }}$ and increased $\mathrm{T}_{\max 2}$ compared to pure PA6, indicating that the thermo-oxidative stability of the composite material decreased at the beginning of the degradation but increased in the second decomposition step. EOP did not affect the amount of char residue at $800{ }^{\circ} \mathrm{C}$. The presence of $\mathrm{ZP}$ in the composite did not change the decomposition temperatures, but increased the amounts of char residue in both decomposition steps. Different mechanisms of the EOP and ZP activity were also expressed in the case of the sample $\mathrm{PA} / 2 \mathrm{P}+2 \mathrm{SI}$, where they were present in combination.

\section{Acknowledgements}

This work was supported by the Slovenian Research Agency - Slovenia (Programme P2-0213, Infrastructural Centre RIC UL-NTF) and the European COST Action FLARETEX (MP1105) "Sustainable flame retardancy for textiles and related materials based on nanoparticles substituting conventional chemicals".

\section{References}

1. HORROCKS, A. Richard. Textiles. In: Fire retardant materials. Edited by A. Richard Horrocks and D. Price. Cambridge : Woodhead Publishing, 2001, 128-181.

2. HORROCKS, A. Richard. Flame retardant challenges for textiles and fibres: New chemistry versus innovatory solutions. Polymer Degradation and Stability, 2011, 96(3), 377-392, doi: 10.1016/j.polymdegradstab.2010.03.036.

3. HORROCKS, A. R., KANDOLA, B. K., DAVIES, P. J., ZHANG, S., PADBURY, S. A. Developments in flame retardant textiles - A review. Polymer Degradation and Stability, 2005, 88(1), 3-12, doi: 10.1016/j.polymdegradstab.2003.10.024.

4. BAR, Mahadev, ALAGIRUSAMY, R., DAS, Apurba. Flame Retardant Polymer Composites. Fibers and Polymers, 2015, 16(4), 705-717, doi: 10.1007/s12221-015-0705-6.

5. LEVCHIK, S. V, LEVCHIK, G. F., BALABANOVICH, A. I., CAMINO, G., COSTA, L. Mechanistic study of combustion performance and thermal decomposition behaviour of nylon 6 with added halogen-free fire retardants. Polymer Degradation and Stability, 1996, 54(2-3), 217-222, doi: 10.1016/s0141-3910(96)00046-8.

6. MORGAN, Alexander B., GILMAN, Jeffrey W. An overview of flame retardancy of polymeric materials: Application, technology, and future directions. Fire and Materials, 2013, 37(4), 259279, doi: 10.1002/fam.2128.

7. SAMYN, F., BOURBIGOT, S. Protection mechanism of a flame retarded PA6 nanocomposite. 
Journal of Fire Sciences, 2013, 32(3), 241-256, doi: 10.1177/0734904113510685.

8. CHEN, Jun, LIU, Shumei, ZHAO, Jianqing. Synthesis, application and flame retardancy mechanism of a novel flame retardant containing silicon and caged bicyclic phosphate for polyamide 6. Polymer Degradation and Stability, 2011, 96(8), 1508-1515, doi: 10.1016/j.polymdegradstab. 2011.05.002.

9. THEIL-Van NIEUWENHUYSE, P., BOUNORLEGARÉ, V., BARDOLLET, P., CASSAGNUU, P., MICHEL, A., DAVID, L., BABONNEAU, F., CAMINO, G. Phosphorylated silica/polyamide 6 nanocomposites synthesis by in situ sol-gel method in molten conditions: Impact on the fire-retardancy. Polymer Degradation and Stability, 2013, 98(12), 2635-2644, doi: 10.1016/j. polymdegradstab.2013.09.027.
10. ZHAN Zhaoshun, XU Miaojun, LI Bin. Synergistic effects of sepiolite on the flame retardant properties and thermal degradation behaviors of polyamide 66/aluminum diethylphosphinate composites. Polymer Degradation and Stability, 2015, 117, 66-74, doi: 10.1016/j.polymdegradstab. 2015.03.018.

11. SEEFELDT, Henrik, DUEMICHENB, Erik, BRAUN, Ulrike. Flame retardancy of glass fiber reinforced high temperature polyamide by use of aluminium diethylphosphinate: thermal and thermo-oxidative effects. Polymer International, 2013, 62(11), 1608-1616, doi: 10.1002/pi.4497.

12. RUSU, Gheorghe, RUSU, Elena. Anionic nylon 6/ $/ \mathrm{TiO}_{2}$ composite materials: effects of $\mathrm{TiO}_{2}$ filler on the thermal and mechanical behaviour of the composites. Polymer Composites, 2012, 33(9), 1557-1569, doi: 10.1002/pc.22292. 